\title{
La formación literaria en el máster universitario en profesor/-a de Educación Secundaria: reflexiones y propuestas
}

\author{
Prestakuntza literarioa Bigarren Hezkuntzako Irakasletzako \\ Unibertsitate Masterrean: gogoetak eta proposamenak \\ Teaching and learning literature in the Master's Degree in Secondary \\ Education Teacher Training: reflections and proposals
}

\author{
Anna Devís-Arbona \\ ELCIS-Universitat de València \\ anna.devis@uv.es \\ https://orcid.org/0000-0002-0942-565X \\ Josep-Vicent Garcia-Raffi \\ ELCIS-Universitat de València \\ jogaraf@uv.es \\ https://orcid.org/0000-0001-5821-5221
}

Recibido / Noiz jaso den: 30/06/2021

Aceptado / Noiz onartu den: 23/10/2021

\section{Resumen}

Es necesario reconsiderar el Máster Universitario de Formación del Profesorado de Educación Secundaria Obligatoria, Bachillerato, Formación Profesional y Enseñanza de Idiomas (MAES), destinado a la formación inicial del profesorado en las diversas áreas curriculares; en nuestro caso, la especialidad de lengua catalana en la Universitat de València. A tal efecto, hemos elaborado cuestionarios de respuesta semiabierta y textos de respuesta abierta producto de la reflexión de la enseñanza de educación literaria recibida y de la realización de las prácticas escolares con el fin de evaluar el grado de cumplimiento de las expectativas de los estudiantes y, como consecuencia, incorporar medidas de mejora que propicien una formación más adecuada de los futuros profesores de secundaria. Estudiamos la composición del alumnado y su concepción de la educación literaria y la literatura infantil y juvenil, los contenidos explicados, cómo se puede generar la reflexión necesaria sobre la educación literaria y cómo puede aplicar el futuro profesor las herramientas para aumentar la competencia literaria de los alumnos de secundaria y bachillerato. Un análisis de los resultados muestra que, pese a los esfuerzos realizados, todavía quedan aspectos susceptibles de mejora, por lo que se impone un proceso de reflexión sobre ellos, no solo en el seno de cada especialidad, sino en el conjunto de las relaciones que dichas especialidades establecen con las demás secciones del máster (materias genéricas, prácticas, etc.).

\section{Palabras clave}

Programa de formación de docentes de secundaria; educación lectora y literaria; autobiografía lectora; LIJ y formación literaria.

\section{Sumario}

1. Contextualización. 2. Objetivos. 3. Marco teórico. 4. Metodología. Participantes e instrumentos 5. RESULTADOS Y DISCUSIÓN. 5.1. La trayectoria formativa, profesional y los intereses previos en la formación literaria. 5.2 Los conocimientos de LIJ y la formación literaria. 5.3 Autobiografía lectora y formación literaria. 5.4 Resultados después de la finalización de educación literaria. 5.5 Una reflexión posprácticum 6. A MODO DE CONCLUSIONES. REFERENCIAS. 


\begin{abstract}
Laburpena. Beharrezkoa da Derrigorrezko Bigarren Hezkuntzako, Batxilergoko, Lanbide Heziketako eta Hizkuntzen Irakaskuntzako Irakasletzako Unibertsitate Masterra (BHIUM) berraztertzea, irakasleei curriculumeko zenbait arlotan hasierako prestakuntza ematera bideratua dagoen masterra; gure kasuan, katalan hizkuntzaren espezialitatean, Valentziako Unibertsitatean. Horretarako, erantzun erdiirekiko galdetegiak eta erantzun irekiko testuak prestatu ditugu, jasotako hezkuntza literarioaren irakaskuntzari buruz hausnartu eta eskola-praktikak egin ondoren erantzutekoak, ikasleen itxaropenen betetzemaila ebaluatzeko eta, ondorioz, hobekuntzaneurriak txertatzeko Bigarren Hezkuntzako etorkizuneko irakasleei prestakuntza egokiagoa ematearren. Aztertu dugu ikasleen osaera eta hezkuntza literarioari eta haur eta gazte literaturari buruz duten ikuskera, azaldutako edukiak, nola sortzen ahal den hezkuntza literarioari buruz beharrezkoa den hausnarketa eta nola aplikatzen ahal dituen etorkizuneko irakasleak Bigarren Hezkuntzako eta Batxilergoko ikasleen gaitasun literarioa handitzeko tresnak. Emaitzak aztertu ondoren, ikusi da ezen, ahaleginak egin diren arren, oraindik hobetzen ahal diren alderdiak badaudela, eta, beraz, horiei buruzko hausnarketa-prozesu bat ezarri beharra dagoela, ez bakarrik espezialitate bakoitzaren barnean, baita espezialitate horiek masterreko gainerako atalekin ezartzen dituzten erlazioetan ere (ikasgai generikoak, praktikak, etab.).
\end{abstract}

Gako hitzak. Bigarren Hezkuntzako irakasleak prestatzeko programa; Irakurketa eta Literatur Hezkuntza; Irakurketa autobiografia; HGL eta literatur prestakuntza.

\begin{abstract}
It is necessary to reconsider the Master's Degree in Teacher Training in Compulsory Secondary Education, Baccalaureate, Professional Education and Language Teaching (MAES), aimed at initial teacher training in the several curricular areas, in our case, the specialty of Catalan language, at the University of Valencia. To this end, we have developed semi-open-ended response questionnaires and open-ended response texts to evaluate the fulfilment of students' expectations after their classes on literary education and their school practices, and hence, incorporate measures to promote and improve a more adequate training of future secondary school teachers. We study the diversity among students and their conception of literary education, children's and young people's literature and their contents, as well as how the necessary reflection on literary education can be generated and how the future teacher can apply different tools to increase the literary competence of secondary and baccalaureate students. An analysis of the results shows that, despite the efforts made, there are still aspects that can be improved, so more reflection on them is required, not only within each specialty but also on the relationships that these specialties establish with other sections of the master's degree (generic subjects, internships, etc.).
\end{abstract}

Keywords. Secondary Teacher Training Program; Reading and Literary Education; Reading Autobiography; LIJ and Literary Training.

\section{Contextualización}

Durante el curso 2009-2010, en las universidades españolas se desarrolló por primera vez el MAES que, tal como hoy lo entendemos, se deriva de la Orden ECI/3858/2007, de 17 de diciembre (BOE n. ${ }^{\circ}$ 305, 21 de diciembre de 2007), por la que se establecen los requisitos para la verificación de los títulos oficiales que habilitan para el ejercicio de Profesor/-a de Educación Secundaria Obligatoria y Bachillerato, Formación Profesional y Enseñanza de Idiomas. Todo ello coincidía con la idea, cada vez más presente en las políticas educativas del entorno internacional, de que los docentes constituyen el eje de la calidad educativa y que, por lo tanto, es preciso repensar su formación inicial (Furlong, Cochran y Brennan, 2009; Ball y Forzani, 2009; Barber y Mourshed, 2007); y con el debate generado entonces por la implantación del Espacio Europeo de Educación Superior (González, 2010). 
En España, hacía tiempo que era imprescindible atender a una nueva enseñanza secundaria diferente a cómo se había entendido: diferente porque es una «educación general básica» y porque comporta un bachillerato «concebido no tanto como un proceso selectivo, sino como 'puente general' para una enseñanza universitaria que se ha generalizado también» (González, 2010, p. 21). En su momento inicial, el nuevo escenario se consideró en ocasiones como «una oportunidad histórica» (Manso y Martín, 2014, p. 147) de abandonar el modelo representado por el Curso de Aptitud Pedagógica (CAP), denostado hacía tiempo.

El nuevo máster pasaba de ocupar unos pocos meses a estar compuesto por 60 créditos a lo largo de todo un curso (ANECA 2012); las prácticas cobraban un mayor protagonismo y obligaba a la elaboración de un TFM que suponía para el alumno el inicio de la vinculación de la docencia y la investigación. No obstante, también han sido diversas las críticas recibidas por el MAES desde su nacimiento, y que lo presentaban como una (otra) oportunidad perdida desde el origen; en especial, se lamentaba el no haber apostado por un grado específico de formación de profesorado y haber mantenido con el máster el carácter de formación.

En el caso de la Universitat de València, a raíz de la citada orden ECI, se inició el proceso de elaboración del plan de estudios que conformaría finalmente el máster. La historia de este proceso se ha revelado compleja en todo momento; las condiciones iniciales de implantación no eran halagüueñas, y muchos de los problemas detectados en esos momentos iniciales no han sido solucionados todavía (instalaciones deficitarias, problemas de coordinación, falta de personal, etc.). En este sentido, es destacable la complejidad inherente a este máster en cuanto a su organización, relaciones entre profesorado de muy diverso origen, implicación de tiempos y espacios muy diferenciados, etc.

Es preciso tener en cuenta, en este sentido, que los alumnos del MAES suponen alrededor de un $15 \%$ del alumnado total de máster de la UV, un número proporcionalmente iǵual o mayor al de alumnos matriculados en algunas facultades: por ejemplo, según el Anuari de dades estadístiques del curso 2019-2020 publicado por la UV, los alumnos matriculados en el máster eran 800, máximo de alumnos permitidos, quedando muchos de ellos sin posibilidad de acceso, frente a los 413 de la Facultad de Matemáticas o los 168 de la Facultad de Física. Tal volumen de estudiantes implica la participación de casi 1000 profesores, entre docentes universitarios y tutores de prácticas, provenientes de muy diversas situaciones laborales y tradiciones académicas, y repartidos en 24 especialidades. No obstante, el compromiso y la implicación de la mayoría del personal que trabaja en el máster desde sus distintas instancias (CCA, PAS, coordinación de espacialidades, coordinación de materias, docentes...) está detrás de su acreditación positiva por parte de la ANECA en el año 2015.

En este contexto, y con el propósito de contribuir al proceso de análisis y mejora de nuestro máster, nos preguntábamos con qué expectativas llegan los 
alumnos, qué aspectos valoran positivamente en la formación literaria y qué consideran que no se ajusta a la labor que van a tener que desempeñar. A veces, el alumno del máster confía ingenuamente en que no necesitará de mucho más que de sus conocimientos para poder defenderse como profesionales de la docencia. Es esta falta de contacto con la realidad del aula, que priva al alumno de una visión correcta de los problemas con los que deberá enfrentarse en su práctica docente, la que provoca, paradójicamente, la minusvaloración de las estrategias que el máster le ofrece. Los profesores del máster presentan al alumno como realidades situaciones en el aula que no ve sino como hipotéticas.

La preparación recibida por el futuro profesor novel ha estado esencialmente académica. Ha sido explicado ad nauseam la separación existente entre el mundo académico y el de las aulas, las ausencias dentro de la preparación académica de las técnicas y actitudes necesarias para actuar eficazmente con el alumnado, la separación existente entre los conocimientos aprendidos en la carrera y la aplicación de estos conocimientos en la realidad del aula dentro del nuevo rol de profesor. En nuestro caso, el análisis se ciñe a los alumnos de la especialidad de Lengua y Literatura Catalanas y, en concreto, en la materia de formación literaria de la asignnatura de Aprendizaje y Enseñanza de la Lengua y la Literatura Catalanas (valencianas) que tiene 16 créditos.

\section{Objetivos}

Como profesores de la especialidad de Lengua Catalana, y con el objetivo último de mejorar nuestras prácticas en distintos niveles, en el presente trabajo nos planteamos indagar cuáles eran las creencias y las expectativas de los estudiantes de la Universitat de València que cursan el máster en esta especialidad y en la materia de Educación Literaria. A tal efecto, hemos elaborado dos encuestas semiestructuradas al inicio de la asignatura del curso 2019-2020 y tres textos de redacción semiguiada a lo largo del periodo de clases y al final con el fin de evaluar el grado de cumplimiento de las expectativas de los estudiantes y, como consecuencia, incorporar medidas de mejora que favorezcan una formación más adecuada de los estudiantes, futuros profesores de secundaria. Por consiguiente, los objetivos de nuestro estudio son los siguientes:

- Valorar las creencias y expectativas de los estudiantes del máster de la UV en la especialidad referida a la L1.

- Reflexionar sobre los aspectos que convendría mejorar de acuerdo con las opiniones de los estudiantes, y proponer las medidas que se deriven de ello.

- Comparar el grado de satisfacción de los estudiantes, valorando las expectativas iniciales y los resultados finales. 
Como ya hemos referido, el objetivo de este estudio es analizar las creencias y expectativas en la formación literaria de una muestra de alumnos del MAES de la UV, así como el grado de satisfacción alcanzado tras su realización durante el curso 2019-20, con el fin de detectar las fortalezas y consolidarlas, pero, sobre todo, con la intención de mejorar aquellos aspectos menos satisfactorios en un máster tan complejo como el que nos ocupa.

Las conclusiones nos permitirán incorporar medidas de mejora que propicien una formación más adecuada de los futuros profesores de secundaria, una profesión que, a pesar de los obstáculos, sigue suscitando interés y debate entre la comunidad educativa, en particular, y entre la sociedad, en general. Una educación verdaderamente democrática debe asumir el reto de abordar una serie de decisiones desde una perspectiva respetuosa, inclusiva y transformadora. La educación ha de entenderse como el instrumento que vela por el efectivo desarrollo competencial personal del alumno para que pueda desenvolverse de manera óptima en un mundo diverso y cambiante.

\section{Marco teórico}

Este máster de la Universitat de València (2014) tiene 60 créditos que se reparten de la siguiente manera: 16 obligatorios, 28 optativos de la materia profesional, seis del Trabajo Fin de Máster y diez de las Prácticas externas. Los tres módulos genéricos y obligatorios son: Aprendizaje y Desarrollo de la Personalidad, Procesos y Contextos Educativos y Sociedad, Familia y Educación, además de las tres asignaturas específicas de la materia profesional. Desde la didáctica de la lengua y la literatura y la educación linguiística y literaria se repasan los principales recursos para la investigación, la bibliografía especializada más útil y el análisis y la producción de diferentes diseños de investigación.

El alumno debe ser considerado como investigador docente, y ello supone suministrarle el caudal bibliográfico sobre la didáctica específica que su materia está produciendo. Una información contrastada sobre las tendencias y principales orientaciones en la investigación didáctica de las materias que deberá impartir, de los libros fundamentales que se hayan ido generando en su disciplina, de las revistas que existen en ella y de los congresos y foros de discusión fundamentales.

El Aprendizaje y enseñanza de la lengua y la literatura se divide en tres grandes bloques: 1. Los fundamentos teóricos y metodológicos de la didáctica de la lengua y la literatura y su aplicación al currículum de secundaria. Se explican además los aspectos referidos a la planificación de los contenidos lingüuísticos y literarios; desde los programas específicos, la atención a la diversidad 
o la evaluación de los contenidos programados. 2. Los conceptos básicos de la educación linguiística como, por ejemplo, la competencia lingüuística y comunicativa o los enfoques metodológicos de la enseñanza de la lengua. Por otro lado, se realizará un recorrido por los recursos y estrategias propias de la enseñanza de las habilidades lingüuísticas en Educación Secundaria. 3. Los conceptos básicos de la educación literaria como, por ejemplo, la competencia lecto-literaria y los enfoques metodológicos de la enseñanza de la literatura y un recorrido por los recursos y estrategias propias de la educación literaria en la enseñanza secundaria.

Se plantea aquí, en este tercer bloque de la asignatura, la educación literaria como una alternativa a la enseñanza de la literatura establecida tradicionalmente en los planes de estudio. El peso de la tradición mantiene todavía en muchas aulas una inercia que tiende a orientar las prácticas de enseñanza/aprendizaje hacia la adquisición de conocimientos centrados en las obras y los autores. Este enfoque tradicional se aleja mucho de los nuevos, que sitúan el objetivo fundamental en el hecho de que el alumno se convierta en un lector competente. Desde esta nueva perspectiva, centrada en el receptor, la educación literaria quedará definida como la preparación para saber participar con efectividad en el proceso de recepción y de actualización interpretativa del discurso literario. Una educación literaria que suponga también reforzar la idea de la lectura como actividad placentera, el aprendizaje de la construcción del sentido del texto (elaborado por el lector y el contexto histórico, cultural y literario enmarcados) y el estudio de la obra desde el punto de vista formal, genérico, retórico. En este contexto educativo la enseñanza-aprendizaje de la literatura (Ballester e Ibarra, 2009, p. 34):

debe configurarse por la pluralidad de voces, metodologías y textos, sin que esto implique, en modo alguno, el cumplimiento forzoso de determinadas cuotas, ya sean estas étnicas, genéricas o culturales. La educación literaria en el siglo XXI representa una respuesta comprometida con las transformaciones socio-históricas contemporáneas y, sobre todo, con un diálogo con la sociedad circundante.

Los modelos didácticos actuales, incluso con la aportación de los nuevos enfoques de los últimos años, no resultan todavía eficaces ni responden a las necesidades de una formación literaria y personal. La renovación didáctica para la formación literaria ha permanecido anclada en supuestos tradicionales, fundamentalmente de tipo historicista, alrededor de los cuales se han vehiculado algunas aportaciones. El eje formado por el autor, la obra y el lector es la base sobre la que la didáctica de la literatura ha apoyado todo su edificio teórico y metodológico. Como hemos comentado anteriormente, en el máster estudiamos las bases 
de la educación literaria, desde la competencia lecto-literaria a la educación literaria sin descuidar los enfoques metodológicos de la enseñanza de la literatura. Pero el contenido literario principal en esta asignatura es la educación literaria en la enseñanza secundaria. Es a partir de las prácticas cuando el alumno ve que los contenidos teóricos de las asignaturas del máster han dado resultado y están en continua contrastación con la actividad en el aula. El choque que produce el contacto con ella, en definitiva, con la realidad humana del alumnado, es tal que produce un cambio sustantivo en la mayoría de los alumnos, al descubrir de súbito la ausencia de recursos que les hagan capaces de explicar y hacer en clase todo lo que ellos desearían hacer.

\section{Metodología: participantes e instrumentos}

Hemos realizado unos cuestionarios de respuesta semiabierta -como ya realizamos en una anterior investigación (Devís y Morón, 2020)- y textos de respuesta abierta producto de la reflexión de la enseñanza de educación literaria recibida y de la realización de las prácticas escolares. El primer cuestionario era una ficha personal con la titulación de la que provenían, la relación entre su actividad laboral, cuando existía, y la profesión docente y las razones que les habían impulsado a realizarlo. Además, el cuestionario planteaba aspectos relativos a las creencias y expectativas que los estudiantes tenían sobre las materias de la formación literaria en nuestra especialidad, incluido el TFM. El segundo cuestionario recoge los conocimientos previos sobre la literatura infantil y juvenil (LIJ) que tiene nuestro alumnado. Los otros tres documentos que servirán para nuestro trabajo son:

1. Una autobiografía lectora breve y un repaso sobre cómo han recibido la formación literaria durante las diferentes etapas educativas.

2. Una vez finalizadas las clases presenciales, escribieron una reflexión en clase sobre el nivel de satisfacción de la docencia del bloque de formación literaria y la selección de los contenidos metodológicos o estrategias que les habían aparecido más valiosas.

3. Una vez finalizado el periodo de prácticas, nos enviaron un texto de opinión sobre el resultado de esta experiencia.

Los cuestionarios y los textos reflexivos escritos se han aplicado a la totalidad del alumnado matriculado en el máster. Sin embargó, de los 34 alumnos matriculados a principio de curso, cinco de ellos abandonaron la asignatura o no realizaron las prácticas correspondientes por motivos personales o laborales. Y, para ofrecer unos datos más completos, de facto tenemos 29 alumnos con todos los materiales completos. 
Tabla 1. Alumnado

\begin{tabular}{|ccc|}
\hline Sexo & Registros & Porcentaje \\
\hline Mujer & 20 & $70,59 \%$ \\
\hline Hombre & 9 & $29,41 \%$ \\
\hline
\end{tabular}

Tabla 2. Edad del alumnado

\begin{tabular}{|ccc|}
\hline Edad & Registros & Porcentaje \\
\hline $23-25$ & 14 & $50,02 \%$ \\
\hline $26-30$ & 10 & $35,28 \%$ \\
\hline $31-40$ & 4 & $11,76 \%$ \\
+40 & 1 & $02,94 \%$ \\
\hline
\end{tabular}

\section{Resultados y discusión}

\subsection{La trayectoria formativa, profesional y los intereses previos en la formación literaria}

Por lo que respecta a la formación previa al máster, diez alumnos eran de Filología Catalana; ocho, de Comunicación Audiovisual-Periodismo; cinco, provenían del Grado de Educación Primaria (Magisterio); tres, de Filología Hispánica; y tres, de grados de Traducción o Mediación y Lenguas Aplicadas. Es bastante habitual que nuestro alumnado compagine el máster presencial con algún tipo de trabajo. Aunque diez manifiestan que son estudiantes, el resto -19-, anotan algún trabajo a tiempo completo o parcial. De estos, más de una tercera parte -diez- trabaja de profesor de valenciano para adultos en academias que preparan los exámenes para obtener las certificaciones oficiales en lengua catalana. El resto -nueve- tiene ocupaciones muy diversas: desde comercial a administrativo pasando por monitor de tenis o camarero, entre otros. Entre los motivos por los que se han inscrito, prácticamente la totalidad lo ve como una opción de trabajo para después del grado y que cursar el máster es obligatorio para dar clase y opositar. 


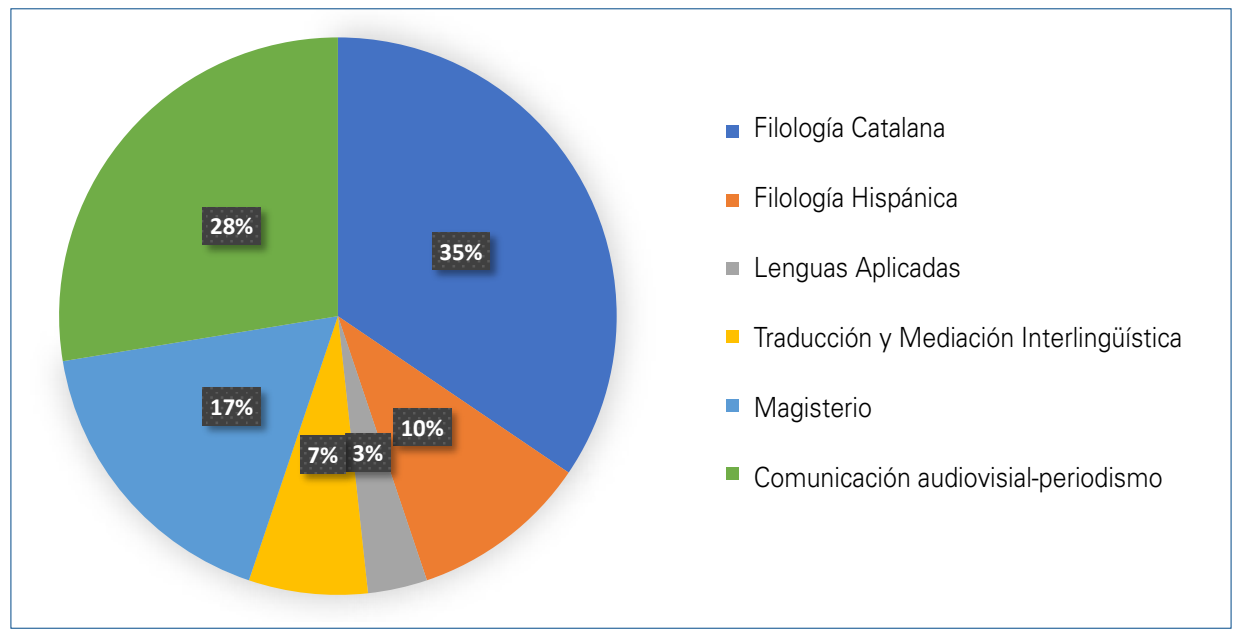

Figura 1. Titulación del alumnado del máster.

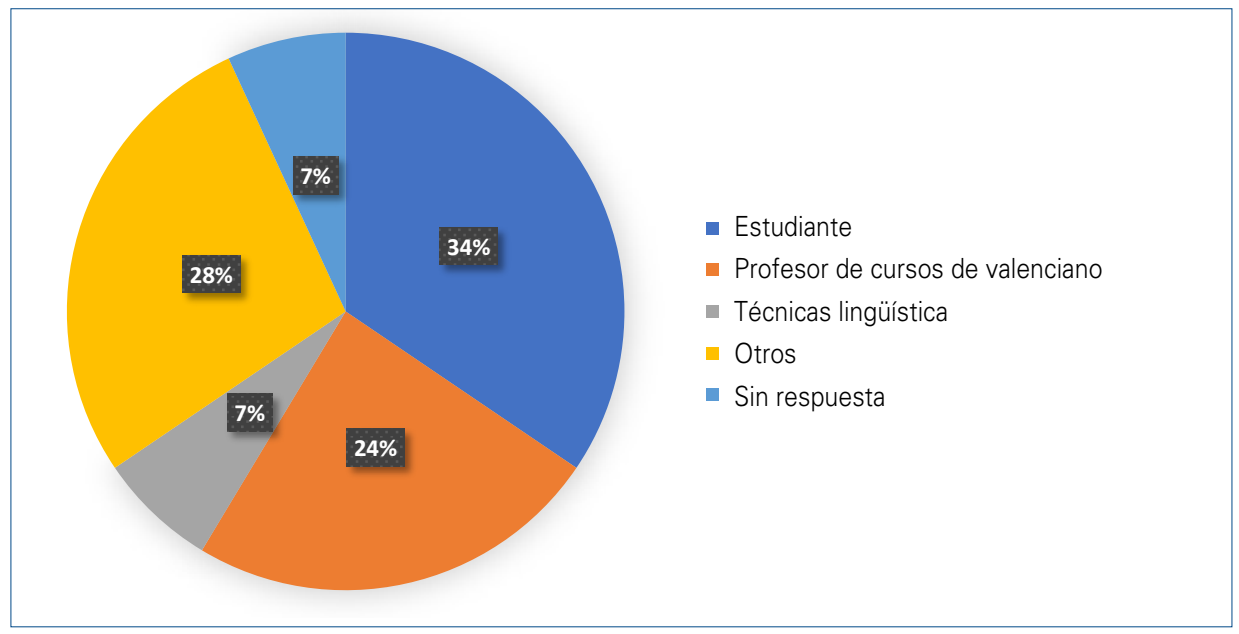

Figura 2. Actividad laboral del alumnado del máster.

El alumnado del máster tiene unos intereses previos antes de recibir las clases de formación literaria. La mitad quiere conocer técnicas de animación lectora, escritura creativa y recursos que promuevan el fomento lector. El resto, a parte de cuatro estudiantes interesados por la LIJ, dudan en responder concretamente. Por lo que respecta al Trabajo Fin de Máster, como el cuestionario se realizó en las primeras clases del curso, cuando solo ha sido explicado muy sucintamente, es más un futuro proyecto lleno de dudas y miedos. 


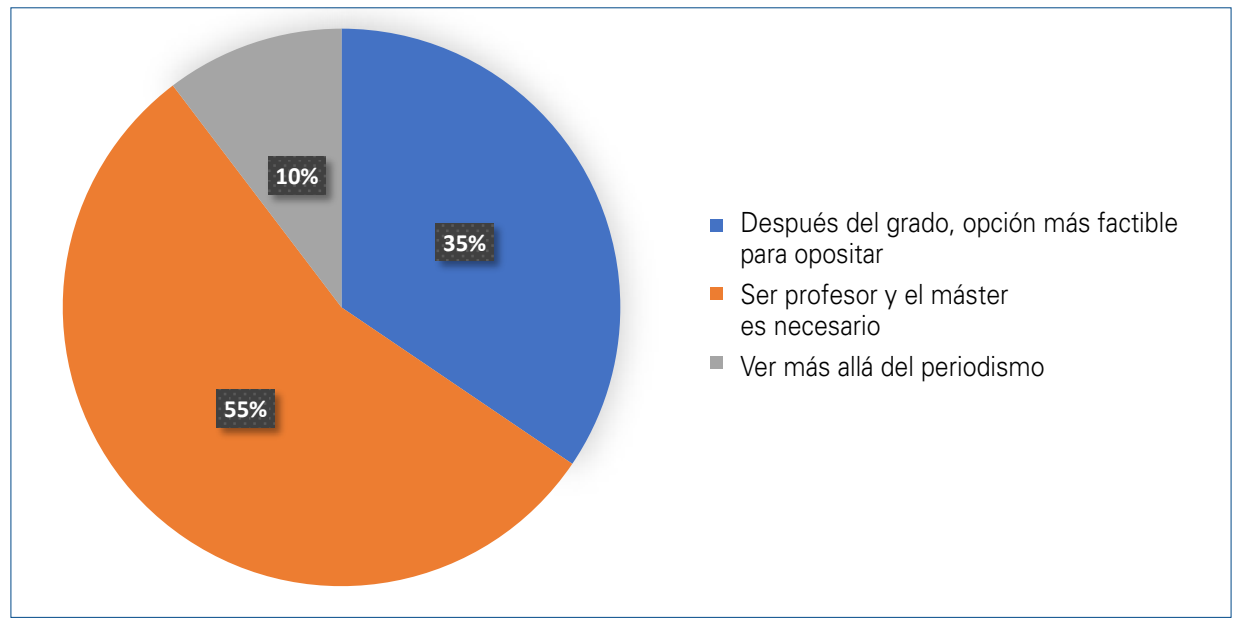

Figura 3. Motivación del alumnado para inscribirse al máster.

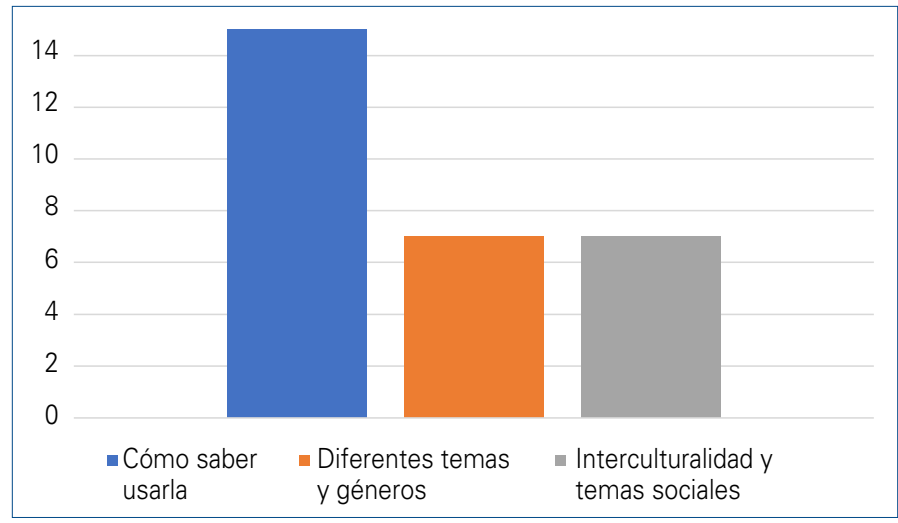

Figura 4. Aspectos de la LIJ que interesan más al alumnado.

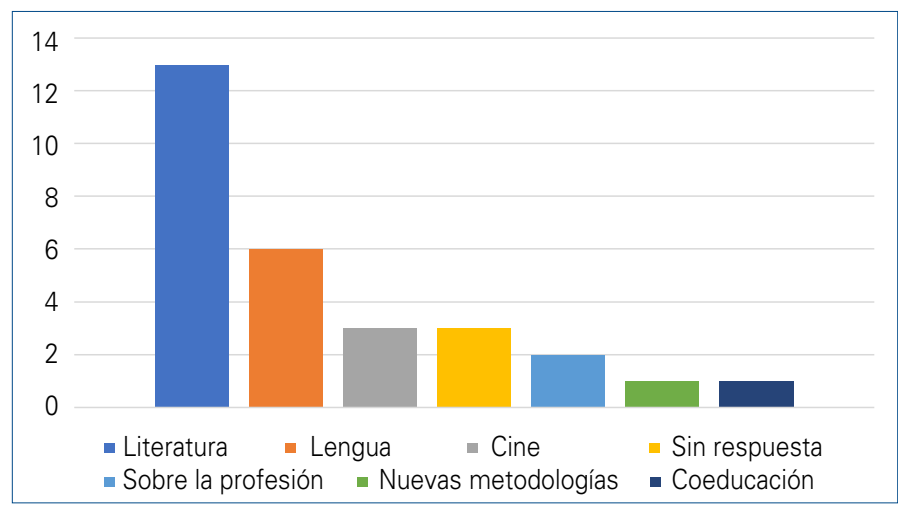

Figura 5. Intereses sobre el TFM. 


\subsection{Los conocimientos de LIJ y la formación literaria}

Hace unos años (Garcia-Raffi, 2014) estudiamos ya el conocimiento y el papel de la LIJ entre los alumnos del Máster de Profesorado de Secundaria. Los alumnos graduados o licenciados que lo cursan tenían, y tienen, una diferente formación literaria y un desigual conocimiento de LIJ. Si el alumno ha tenido una formación filológica o propia del Grado de Maǵisterio, mayoritariamente, aunque no siempre, tiene adquiridos contenidos de LIJ o, incluso, ha cursado una asignatura optativa. Pero actualmente los másteres ligados al mundo laboral, entre los que se encuentra este, reciben alumnos de diferente formación: Traducción, Periodismo y Comunicación Audiovisual... En este caso, la formación sobre LIJ es mínima y ligada a su recuerdo personal como lector en el instituto. Es evidente que será tarea del máster aumentarla. Un cuestionario es un buen método para valorar aproximativamente su conocimiento y valoración. Tratamos que se realice de manera totalmente individualizada, pero, por la disposición del mobiliario, existe la posibilidad de que algunos títulos se repitan por influencia de los compañeros.

Es lógico, que como formadores de futuros profesores, conozcamos las experiencias literarias con la LIJ, los «recuerdos y vivencias, vinculados a relaciones afectivas con personas, a una o varias lenguas o culturas, a las experiencias como lectores y espectadores como referentes intertextuales que aportan los estudiantes» (Díaz y Prats, 2013). Para recuperar esas lecturas, su evolución y el valor de los clásicos en las literaturas que conocen, proponemos habitualmente el siguiente cuestionario del que se hace alguna variación que incluye los mass media:

Tabla 3. Un cuestionario sobre la LIJ

1. ¿Recuerdas alguna lectura de LIJ? ¿Te la recomendó alguien? ¿Por qué te gustó o disgustó? ¿Todavía la recomendarías?

2. Los clásicos de la literatura. Cita un título que consideres clásico de la literatura catalana, española y universal.

3. Los clásicos de la literatura infantil y juvenil. Cita un título que consideres clásico de la literatura LIJ catalana, española y universal.

4. ¿Qué género o subgénero literario de la LIJ te parece más atractivo? ¿Y el tema? ¿Conoces algún título concreto? ¿Y el cómic? ¿Qué títulos recuerdas de los que leías tú y ahora sabes qué cómics leen los jóvenes? ¿Y el libro marca? ¿Recuerdas uno de tu época de lector juvenil? ¿Y de ahora?

Las respuestas analizadas nos dan noticia sobre su formación en LIJ, sus gustos literarios y algunas veces sus referentes audiovisuales en la etapa adolescente, etc. Hemos comparado los resultados del curso 2019-2020 con los recogimos hace cinco años y son semejantes. 
El recuerdo de una obra de la LIJ muestra una total diversificación de títulos y autores, más de veinte diferentes. Se reparten de igual manera entre títulos de autores valencianos o catalanes (Joan Pla, que con su novela Mor una vida es trenca un amor, continúa siendo citado más de una vez; Jordi Sierra i Fabra o el reciente Xavi Sarrià) a obras de la LIJ contemporánea traducidas como Diari d'un jove maniàtic de $\mathrm{A}$. Macfarlane y A. McPherson o de la literatura universal como Romeo y Julieta. En nuestro trabajo anterior, teníamos unas respuestas muy semejantes, pero había literatura ganada (Momo, La isla del tesoro...). El desconocimiento de la LIJ por parte de algún alumnado origina en el cuestionario actual la cita sorprendente de Ensayo sobre la ceguera de Saramago o Muerte en el Nilo de Agatha Christie como literatura juvenil.

Por lo que respecta al mediador que se la ha ofrecido, comentado o animado a leerla, mayoritariamente es adulto y relacionado con el mundo escolar. En un porcentaje bajo, aparece un amigo, un compañero de clase, un familiar o un bibliotecario. También recuerdan esta lectura como atractiva por la facilidad que tenían para identificarse con su protagonista por su edad o los temas (amor, aventura, intriǵa...). Después de cinco años, los resultados son iǵuales.

En este repaso de lecturas, el alumnado del máster coincide en señalar dos títulos como clásicos: Tirant lo Blanc para la literatura catalana y el Quijote para la española. Los dos son citados por más de un $60 \%$ en los dos cuestionarios. Por lo que respecta a la literatura universal, la diversidad de títulos es amplia: desde $L a$ Eneida a Cien años de soledad, sin olvidar La metamorfosis, Drácula, Robinson Crusoe o Edipo Rey, entre otros. En el cuestionario actual, aparece Guerra y Paz de Tolstoi y más veces citados títulos de William Shakespeare. Debemos recordar ahora, y para todo nuestro comentario, que una de las asignaturas optativas del bachillerato valenciano -primero fue en segundo; después, en primero- es Literatura Universal que se imparte tanto por los departamentos de castellano como de valenciano. La lista de libros de lectura obligatoria está presente en las respuestas de estos cuestionarios.

Los títulos que recuerda un estudiante de máster, con una edad que oscila mayoritariamente entre los 23 y 30 años -aunque este curso hay cinco estudiantes más mayores-, como un clásico de la LIJ, son una vez más muy diversos. Es evidente que la literatura ganada, las adaptaciones de clásicos, muy frecuentes en el ámbito educativo, y los libros de lectura -LIJ o no- obligatoria en los últimos cursos del instituto, por ejemplo, los relacionados con la selectividad -PAU o EBAU-, son los referentes mayoritarios. Esto significa que en la literatura catalana hay títulos como Tirant lo Blanc, La plaça del diamant de M. Rodoreda o El perquè de tot plegat de Quim Monzó, obras que no son evidentemente LIJ. Lo mismo sucede con la literatura española con títulos como El Lazarillo, Luces de Bohemia de Valle-Inclán o La casa de los espíritus de I. Allende. Por lo que respecta a lo que consideran clásicos LIJ de la literatura 
universal, vuelve a suceder: Edipo Rey, obras de Shakespeare o Oliver Twist de Ch. Dickens.

En la literatura catalana, hace cinco años -y ahora- sobresalía Mecanoscrit de segon origen de Manuel de Pedrolo o Mor una vida es trenca un amor de Joan Pla, títulos que marcaron el principio del circuito de la literatura recomendada y que sí podemos considerar LIJ. La presencia infantil de los libros de Teo y de Les tres bessones, que eran presentes hace cinco años, prácticamente ha desaparecido. El poco alumnado que cita obras que considera clásicas de LIJ española nombra a Manolito Gafotas de Elvira Lindo, que también aparecía hace cinco años, y ahora títulos de Laura Gallego como Memorias de Idhun y El Valle de los lobos (obras que tienen traducción catalana y son citados también como LIJ catalana).

Por último, la literatura universal, por lo que refiere a la LIJ, da un panorama también plural y ligada a la literatura ganada: desde $E l$ principito (citado por el $20 \%$ del alumnado en los dos cuestionarios) -ahora también Las crónicas de Narnia de C.S. Lewis-, Robinson Crusoe, Drácula, La isla del tesoro, La vuelta al mundo en ochenta días o la serie de Harry Potter...

Es mayoritaria la coincidencia de recomendar la narrativa como el género adecuado para el lector de LIJ y los subgéneros de aventuras, intriga o realista ligada al amor adolescente. Y de narrativa son siempre los títulos que proponen, cosa que coincide con un criterio general (Pagè̀s, 2006, p. 29). Es de destacar, según aparece en los cuestionarios, la novela histórica como un subgénero bien valorado para la LIJ hace cinco años; actualmente, la intriga y el misterio. Cuando piensan en la literatura ligada a una serie, a una marca incluso, anotan mayoritariamente Harry Potter como hace cinco años, pero no saben títulos actuales. Los cómics de Astérix y Obélix y Mortadelo y Filemón -serie más citada hace cinco años- aparecen como más leídos por iǵual en la literatura dibujada, junto a nombres como Zipi-zape, Mafalda o Dragon Ball.

Esta información del alumnado de máster muestra la confusión que se posee respecto a qué es LIJ, o no, o la pertinencia a determinada literatura nacional de un texto concreto ajeno como la serie de Los cinco secretos de Enid Blyton. En la actualidad, han desaparecido la referencia a los cuentos de la tradición popular que reescribió Perrault o los hermanos Grimm. Hay muy poco alumnado -en el cuestionario actual casi nadie- que recuerde las primeras lecturas, las más infantiles, y se centran en las más juveniles, los clásicos adaptados o la literatura ganada. La falta de conocimiento sobre la LIJ es todavía más clara cuando preguntamos que recomienden un título concreto: más del 25\% no sabe citar ninguno. Los que lo hacen anotan, junto a la serie de Harry Potter o obras de Laura Gallego, títulos que, a priori, son alejados de una recomendación LIJ como, por ejemplo, El verí del teatre de R. Sirera, Te deix amor la mar com a penyora de C. Riera o 1984 de G. Orwell. Tienen claro, eso sí, que hay que recomendar los títulos de aventuras, de misterio o narraciones con un grupo juvenil como prota- 
Anna Devís-Arbona y Josep-Vicent Garcia-Raffi

gonista. Desde nuestra posición de profesores de formación literaria en un máster profesionalizador, no podemos dejar de coincidir plenamente con las palabras de C. Aguilar (2020, p. 39) cuando concluye desde la perspectiva de la formación inicial de maestros y maestras afirma que hay dos cuestiones urgentes: a) La educación literaria del estudiantado es imprescindible y, b) para ello, también necesita la adecuada formación teórica y práctica del profesorado de DLL y DLJ.

\subsection{Autobiografía lectora y formación literaria}

Es un estudio exploratorio y diacrónico que empleó la técnica historias de vida para recolectar información acerca de las trayectorias personales y formas de apropiación de la lectura. Según anotan Merino, Barrera y Andrea (2020, p. 3), «desde fines de los años 90, se observa una motivación creciente por estudiar las biografías lectoras de los futuros docentes, a partir de interrogantes que los conectan con su trayectoria pasada y presente, y con su autopercepción como lectores y próximamente profesores». La autobiografía lectora se sitúa dentro del ámbito de la investigación etnográfica dentro de los contextos educativos, «aquella que utiliza el discurso en primera persona, en concreto, relatos de vida o autobiografías lectoras. Se trata de una manera de indagar en la memoria, en la experiencia vivida, en las circunstancias y en el contexto en el que se produjo tanto el proceso lector como su motivación» (Ballester e Ibarra, 2019, p. 12).

Los datos se abordaron a través de un análisis de contenido que estableció categorías estructurales y subcategorías relacionadas con las experiencias lectoras en Educación Primaria, Secundaria y universitaria; los momentos y lugares donde se realiza esa lectura; el rol de los mediadores y el valor atribuido a la literatura. Los principales resultados apuntan a destacar la centralidad de la lectura compartida, el rol mediador de las figuras familiares y la escasa participación de la escuela y la biblioteca en esta tarea. La razón radicaría en la obligatoriedad con que se aborda la lectura en el espacio escolar, alejándola del placer y del goce estético.

1. El inicio de la lectura va ligado mayoritariamente a los padres o algún otro familiar, con un papel especial de la madre. De manera minoritaria, ligado a la biblioteca y a la escuela.

2. Son también frecuentemente los padres -en especial, la madre- los que recomiendas lecturas, autores y visitan las bibliotecas acompañándolos.

3. Los títulos que se citan como primaras obras de lectura son Los tres cerditos, La cenicienta y La caperucita roja.

4. En la escuela primaria se producen las primeras actividades de animación lectora y también aparecen los nuevos títulos como, por ejemplo, Las tres mellizas. 
5. La llegada al instituto supone la aparición generalizada de las lecturas obligatorias y las pruebas evaluadoras posteriores.

6. La ESO, y sobre todo el Bachiller, significa una pérdida del hábito lector personal en beneficio de las lecturas escolares, y más claramente en $2 .^{\circ} \mathrm{de}$ bachiller.

7. La universidad (en grados de Filología, Comunicación Audiovisual o Magisterio) suponen la apertura a una lectura muy diversa, pero, sobre todo, obligatoria, ligada a las asignaturas y especialidades. En este nivel educativo hay una entrada masiva del dispositivo de lectura e-book y una diversidad lingüuística de las lecturas.

8. Aunque la mayoría del alumnado (más del 70\%) es menor de 30 años y, por tanto, su formación literaria es más reciente, muestra una insatisfacción respecto a la formación literaria que han recibido que relacionan con un modelo historicista y una falta mayoritaria de animación lectora en el aula.

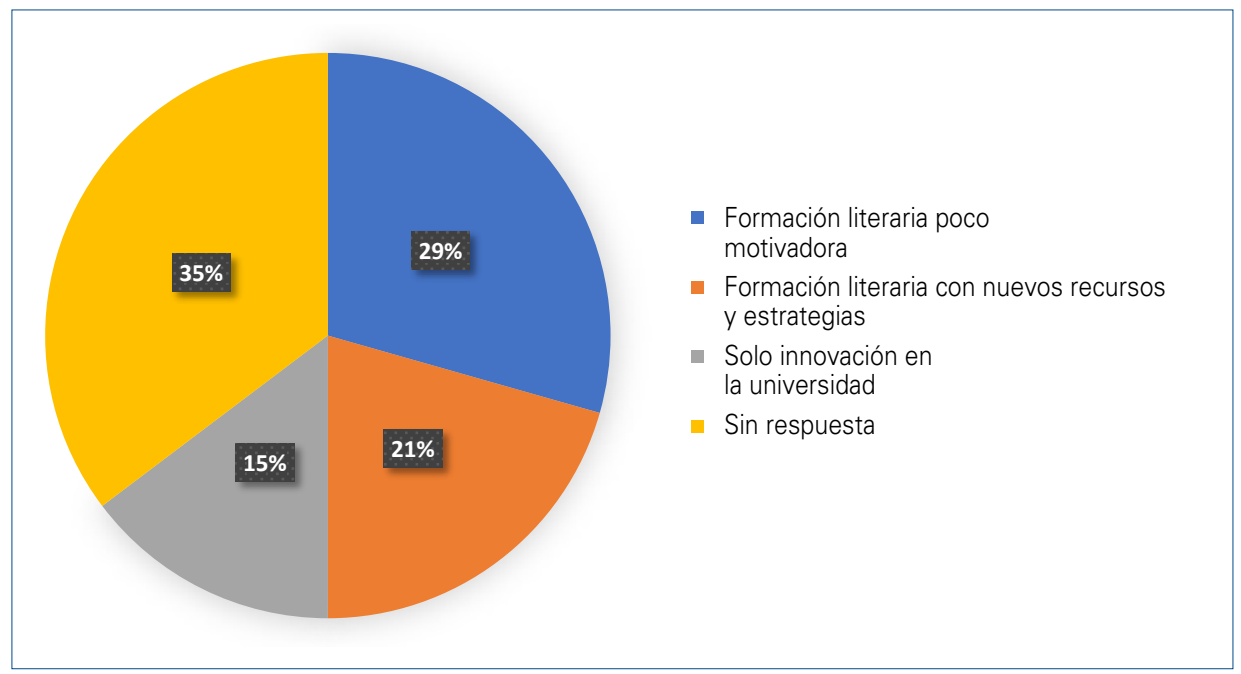

Figura 6. Metodologías de aprendizaje en educación literaria.

\subsection{Resultados después de la finalización de educación literaria}

Una vez finalizadas las clases presenciales, escribieron una reflexión en clase sobre el nivel de satisfacción de la docencia del bloque de formación literaria y la selección de los contenidos metodológicos o estrategias que les habían parecido más valiosas. 


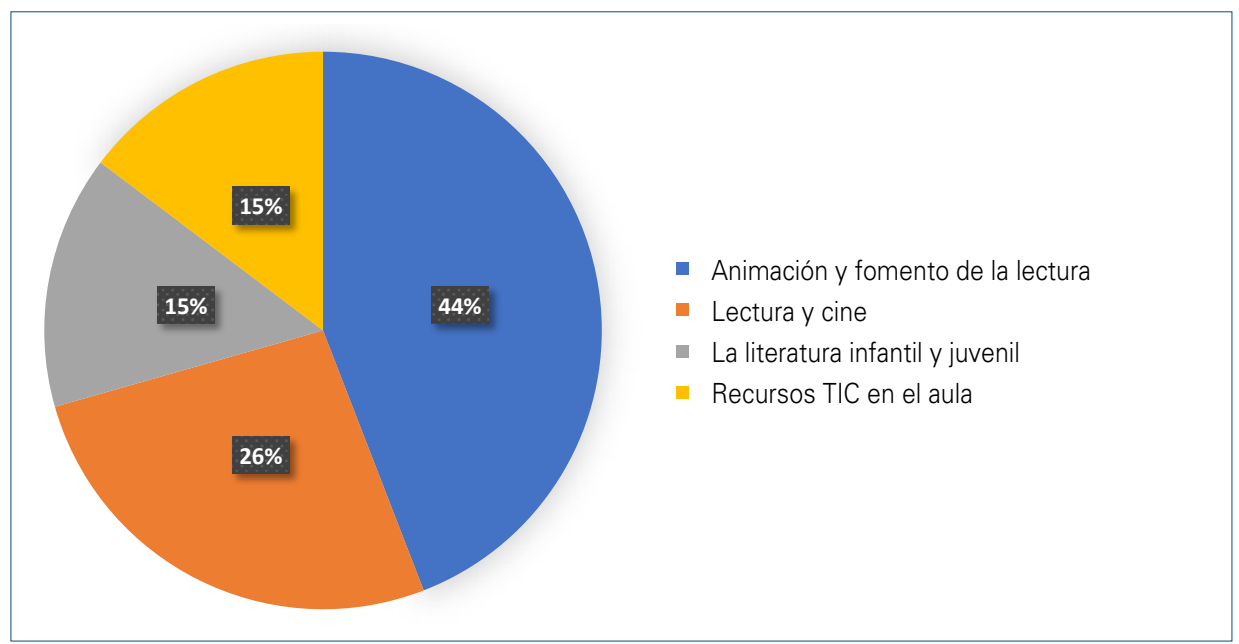

Figura 7. Ítems más valorados de la guía docente.

Son muy críticos con una formación literaria tradicional que liga a los currículums oficiales: la explicación teórica con la realización posterior de ejercicios; los comentarios de texto, la lectura obligatoria con un control de lectura posterior y el examen después de un aprendizaje memorístico. Consideran que la formación literaria en secundaria debería suponer un incremento de la animación lectora y de actividades de fomento de la lectura, el trabajo por proyectos desde la transversalidad y la creatividad y un mayor acercamiento a los clásicos, al cine y al cómic. Además, deberían sugerirse nuevas propuestas de actuación ancladas en la multimodalidad y la conectividad como elementos centrales: herramientas digitales para fomentar la lectura en el aula basadas en la valoración y recomendación de lecturas, plataformas para desarrollar la creatividad literaria y recursos como el booktrailer para presentar los libros... Consideran, finalmente, que hay una escasa presencia de metodologías de aprendizaje en educación literaria en las que se desarrollan las cuatro competencias que le son propias: ética, estética, cultural y lingüuística. Y, por tanto, nuestro alumnado valora positivamente la herramienta metodológica de la secuencia didáctica (Devís, 2009, pp. 35-54) que les ha abierto una nueva perspectiva.

La educación intercultural y plurilingüue constituye un elemento básico que favorece la convivencia cultural y la tolerancia, tan necesarias en nuestra sociedad. Por esta razón, urǵe abordar en las aulas los contenidos relacionados con la adquisición y el desarrollo de la competencia intercultural; y, en este sentido, la educación literaria se erige como instrumento de gran valor. El peso de la tradición mantiene todavía en muchas aulas una inercia que tiende a orientar las prácticas de enseñanza/aprendizaje hacia la adquisición de conocimientos centrados en las obras y los autores. 


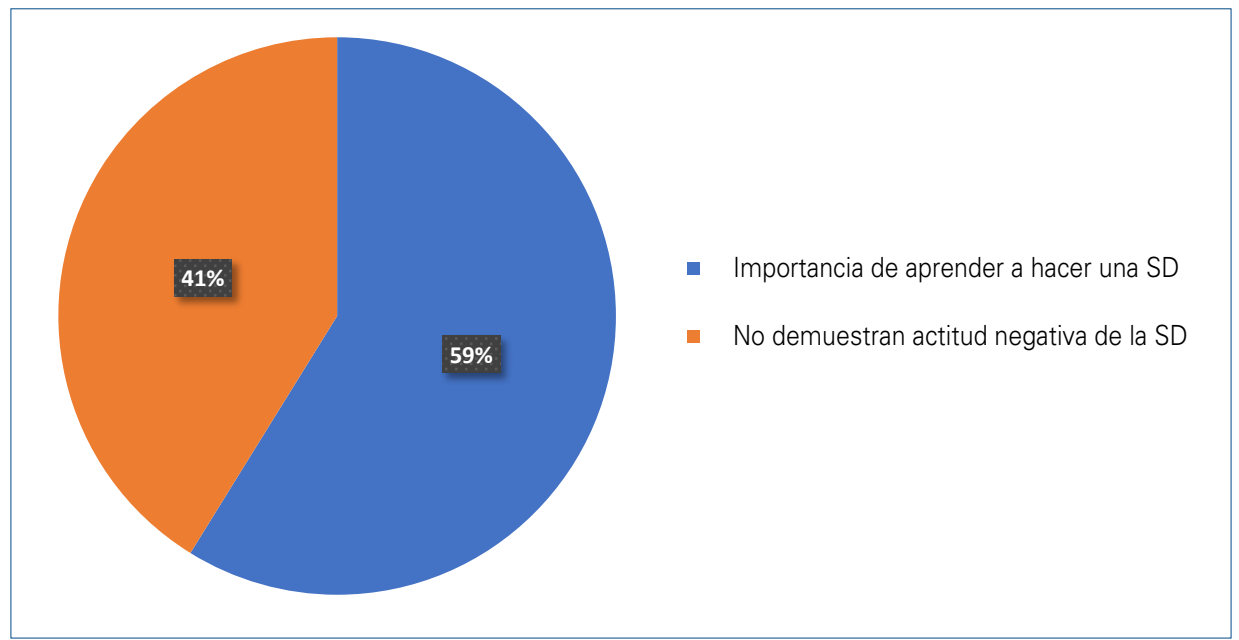

Figura 8. Valoración del alumnado sobre la secuencia didáctica.

\subsection{Una reflexión posprácticum}

Una vez finalizado el periodo de prácticas, nos enviaron a través del aula virtual un texto de opinión sobre el resultado de esta experiencia ${ }^{1}$. La valoración sistemáticamente positiva con que el alumno juzǵa su contacto con el aula, el cambio de mentalidad que contribuye a formar en él y la posibilidad de acceder a las situaciones reales que les esperan son sus elementos más significativos. Las prácticas son, en definitiva, imprescindibles para provocarle la iniciativa docente: esa adecuada combinación de experimentación y control que hace al profesor suficientemente flexible para variar el rumbo y la orientación de sus clases en busca de la eficacia deseada, entre la motivación de sus alumnos y los contenidos. Este periodo les ha servido, pues, para contrastar, experimentar e integrar los aprendizajes teóricos, ensayando la actuación personal y profesional del futuro profesor tanto en el aula como en la dinámica del centro.

1 El curso 2019-2020 ha quedado marcado para siempre por el inicio de la pandemia mundial de la COVID-19 que tanto ha alterado nuestras vidas, que ha supuesto tanta muerte y dolor y que siǵnificó un terremoto en todos los niveles educativos. Casualmente, la asignatura de la que hemos hablado y reflexionado y el periodo de prácticas en el instituto fue inmediatamente anterior al periodo de confinamiento. Por tanto, la pandemia no afectó en ese momento; después, sí en el resto de docencia que tenían y en la realización del TFM. 
Un profesor, al comienzo de su profesión docente, se encuentra con dificultades en la programación de los contenidos adecuados al nivel de sus alumnos, su distribución, las actividades que deben acompañarlos y su evaluación. Así, tiene una falta de las técnicas y recursos necesarios para la enseñanza de las asignaturas del área de lengua y literatura. Desconoce el medio escolar y las posibilidades de interdisciplinareidad dentro del currículum. Con los conocimientos que les proporciona el máster, nuestro alumnado ha aprendido a salvar estas dificultades y lo manifiesta. Esta concepción de la actitud docente hace que el profesor no produzca únicamente conocimiento en el alumnado, sino también en sí mismos y en el resto del profesorado, propiciando así un proceso de autoformación y de formación colectiva.

Nuestros alumnos comprueban, en su periodo de prácticas, que el papel esencial de los profesores es la orǵanización de la interacción de cada uno de los alumnos con el objeto de conocimiento. Esta interacción se concibe como una «mediación», es decir, que la tarea que se lleve a cabo resulte significativa y estimule el potencial del alumno en un trabajo cooperativo de grupo. La experiencia no está reñida con una preparación inicial específica que permita al futuro profesor realizar la transición a su tarea docente con el menor número de errores. Nuestra orientación didáctica no puede sustituir el proceso de adquisición de experiencia en el que el profesor madura como profesional de la docencia. Se trata, entonces, de un conjunto de técnicas adecuadas, una plataforma que le ofrezca una garantía suficiente como para generar su propia experimentación didáctica. A lo largoo de sus años de trabajo, la didáctica de la asignatura cambiará y su papel dentro del sistema educativo; hay que estar dispuesto a adaptarse potenciando en la formación inicial una actitud positiva hacia el cambio.

\section{A modo de conclusiones}

El máster de secundaria debe conseguir como objetivos: una formación básica suficiente; una formación didáctica especializada; una formación psicopedagógica adecuada; una práctica de inducción. Debemos facilitar al alumno la integración de las informaciones internas y externas al aula. Las áreas de conocimiento entendidas como reductos cerrados impiden al alumno ver los lazos que realmente tienen los contenidos, debilitando la capacidad de aprendizaje significativo en aislar los contenidos fuera de estructuras teóricas globales. El instituto necesita un profesor capaz de analizar el contexto en el que se desarrolla su actividad y planificarla, que sabe planificar la comprensión de una enseñanza para todos con atención a la diversidad. Un profesorado dispuesto a enfrentarse a situaciones cambiantes con autonomía profesional, capaz de innovar dentro del aula, de adoptar una actitud positiva ante el reto permanente 
al que está sometido el centro educativo, cambiando sus rutinas y sosteniendo el compromiso en el sistema escolar como organización dentro de una sociedad de progreso.

Los resultados de las diferentes pruebas muestran que, pese a los esfuerzos realizados, todavía quedan aspectos susceptibles de mejora, por lo que se impone un proceso de reflexión sobre ellos (en el seno de la especialidad y de la formación literaria, en particular), además de las relaciones que dichas especialidades establecen con las demás secciones del máster (materias genéricas, prácticas, etc.). Los resultados del estudio tendrán que ser replicados en cursos posteriores para alcanzar una mayor fiabilidad, así como ampliarlos al resto de especialidades del máster para tener una visión más ǵlobal.

Las líneas fundamentales de trabajo en esta formación inicial de los próximos profesores (hay promociones de alumnado que solo en dos meses pasan de la defensa de su TFM final a la entrada como profesor contratado en un aula de secundaria) serán las siguientes:

1. Enseñar las técnicas y los conocimientos didácticos adecuados a las asiǵnaturas enǵlobadas en el área de lengua y literatura, tanto en su orǵanización actual como en las futuras situaciones que se van gestando en el inestable sistema legislativo educativo.

2. Proporcionar las herramientas que le permitan preparar las clases, organizarlas y evaluar los contenidos, su asimilación por parte de los alumnos y su papel dentro del mismo proceso educativo que lleva a término.

3. Familiarizarse con el trabajo en grupo con el resto de los profesores y, en especial, con los profesores de lengua y literatura. Es esencial que el profesor novel adquiera la conciencia de que no puede plantearse su tarea como un hecho aislado en función de sus propios deseos o concepciones, sino que tiene que estar encuadrada en un contexto didáctico más amplio; el marco más cercano es el Departamento de Lengua y Literatura no entendido como un espacio burocrático o administrativo sino como un equipo de trabajo. Solo con coordinación es posible obtener resultados homogéneos, intentar objetivos para todo un ciclo de enseñanza media y marcar los niveles del curso.

4. Apoyar la interdisciplinareidad y planificar los contenidos a través de las TIC.

La vertebración de los contenidos literarios debe situar al receptor en el centro de la selección de estos y superar el omnipresente eje diacrónico en la formación literaria del alumnado. Para ello, la pedagogía intercultural debe ser una realidad latente en el seno de cualquier nivel educativo, ya que, a través de esta herramienta, se persigue la erradicar la segregación, el afecto hacia la hetero- 
geneidad, la valoración de la democracia y el diálogo, la importancia de asumir responsabilidades sociales, etc. El fenómeno de la diversidad cultural y geográfica que define nuestras aulas, que permite el encuentro de personas con experiencias, necesidades y perspectivas muy distintas, resulta de gran ayuda para el reconocimiento de una identidad social múltiple. Más que como una anomalía, lo diverso representa un estímulo en la construcción colectiva de los fundamentos morales para la convivencia. Y en este sentido, la literatura tiene mucho que decir.

\section{Referencias}

ANECA (2012). Sobre la implantación del Máster Universitario de Formación del Profesorado de Educación Secundaria Obligatoria, Bachillerato, Formación Profesional y Enseñanza de Idiomas, análisis de situación y propuestas de mejora. http:// es.scribd.com/doc/88012428/Informe-Master-Secundaria-ANECA

Aguilar, C. (2020). La necesidad de la educación literaria en LIJ en la formación inicial de maestras y maestros. Lenguaje y textos, 51, 29-40.

Ball, D. L., y Forzani, F. M. (2009). The Work of Teaching and the Challenge for Teacher Education. Journal of Teacher education, 60(5), 497-511.

Ballester, J., y Ibarra, N. (2009). La enseñanza de la literatura y el pluralismo metodológico. Ocnos: Revista de estudios sobre lectura, 5, 25-36.

Ballester, J., y Ibarra, N. (2019). Autobiografía y clásicos en la educación literaria de los futuros docentes e investigadores. Tejuelo, 29, 31-66. https://doi. org/10.17398/1988-8430.29.31

Barber, M., y Mourshed, M. (2007). How the World's Best-Performing Systems Come Out on Top. McKinsey \& Company, Social Sector Office.

Devís, A. (2009). Seqüències didàctiques per a comentar textos. Lenguaje y textos, 30, 35-54.

Devís A., y Morón, E. (2020). Creencias y expectativas en el máster universitario de profesorado de educación secundaria: un estudio de caso. En G. de la Maya y M. López Pérez. (Coord.). Del multiculturalismo a los mundos distópicos. Temas actuales de la didáctica de la lengua y la literatura (pp. 61-74). Marcial Pons.

Díaz-Plaja, A., y Prats, M. (2013). Recordar, aprender, practicar: qué sabe y qué debe saber un futuro maestro. Lenguaje y textos, 38, 19-25.

Furlong, J., Cochran-Smith, M., y Brennan, M. (Eds.). (2009). Policy and Politics in Teacher Education: Internacional Perspectives. Routledge.

Garcia-Raffi, J. V. (2014). La LIJ como complemento específico en la formación del profesorado del MAES. Lenguaje y Textos, 39, 9-18.

González, I. (Coord.). (2010). El nuevo profesor de secundaria: la formación inicial docente en el marco del EEES. Graó. 
Manso, J., y Martín, E. (2014). Valoración del Máster de Formación del Profesorado de Educación Secundaria. Estudio de casos en dos universidades. Revista de Educación, 364, 145-169.

Merino, G., Barrera, S., y Albornoz, G. A. (2020). Trayectorias personales de lectura: autobiografías lectoras de estudiantes de pedagogía en una universidad chilena. Álabe, 22. https://doi.org/10.15645/Alabe2020.22.2

Pagès, V. (2006). De Robison Crusoe a Peter Pan. Un cànon de literatura juvenil. Proa.

Universitat de València. (2014). Màster universitari de professor/-a de secundària. http:// www.uv.es/uvweb/master-profesorat-secundaria/ca/master-universitari-profesorat-secundaria-1285886102735.html [recuperado 25-04-2021].

Universitat de València. (2020). Recull de Dades Estadístiques de la UV. https://www. uv.es/uvweb/servei-analisi-planificacio/ca/estadistiques-indicadors/recull-dades-estadistiques-uv/recull-dades-estadistiques-uv-1285868428356.html [recuperado 25-04-2021]. 
